\title{
Academic Collaboration with African Universities
}

\begin{abstract}
AD BOEREN
Ad Boeren is Senior Policy Officer of Nuffic, The Netherlands. E-mail: aboeren@nuffic.nl.

Over the years, collaboration between academic institutions in the global North and institutions in Africa has been characterized by an evolutionary process from pure capacity building to equal partnerships, from social commitment to matching interests, and from specific needs to global strategies. A brief review of this process against the backdrop of global changes and higher education challenges provides a better understanding of the present opportunities and constraints.
\end{abstract}

\section{THE EARLY Years}

Shortly after World War II, when most African countries gained independence, support from the North was rendered for the training of skilled manpower. Scholarships were provided to African students for studies in the North, with the expectation that upon return the graduates would contribute to the development of their respective countries. Young universities in Africa were assisted in setting up facilities, developing curricula, and training staff.

In those early years, a commitment to help build the higher education sector in developing countries was cultivated at universities in the North, as part 
of their institutional mission. If not from their own resources, they financed collaborations through development cooperation funds that were made available by their national governments. Many governments in Northern countries set up scholarship and cooperation programs in higher education and research, which were meant to strengthen capacity in developing countries.

\section{Changes}

Since those early days, the world (of higher education) has changed substantially. Access to higher education has expanded tremendously-in the North as well as in Africa-while funds have not increased proportionately. In the late 1970s, the higher education sector in sub-Saharan Africa was affected by budget cuts, due to economic crises and by parallel reductions of donor support for higher education. As from the 1990s the donor community, led by UNESCO and the World Bank, embraced basic education as their focus of human capacity development, because investments in primary education were assumed to render a higher rate of economic return than higher education. Achieving universal primary education was declared one of the United Nations Millennium Development Goals in 2000. Gradually, the interest of the World Bank for higher education returned, but at a more modest scale than before.

In the same period, other changes took place in the North, which affected the collaboration with African universities. In many Northern countries, governments decided to change the formula for higher education funding from input to output financing. Higher education institutions were thus encouraged to gain extra funds through marketing practices and public private partnerships. Internationalization of higher education became a new focal point for many 
institutions in Europe and elsewhere. Institutions, curricula, students, and staff needed to become international, in order to improve the quality of education and to stimulate international mobility. In Europe, the Bologna process was initiated in 1999 to create one higher education area throughout the continent.

These changes in education policies and funding forced Northern academic institutions to reconsider their priorities and strategies, regarding international cooperation. They had to become more selective in maintaining areas of expertise and in pursuing collaborations with partners. It was considered more advantageous to collaborate with prestigious academic institutions and partners in richer countries (or BRICs-Brazil, Russia, India, and China) than with low-reputation colleagues in poor countries.

At the same time, development donors narrowed down the main objectives of the cooperation programs in higher education that they funded. The development cooperation money should be fully dedicated to the needs of developing countries and no longer be used to "co-finance higher education institutions in the North."

This shift in donor policies has diminished the opportunities for Northern institutions to use collaboration project funds, in order to pursue their own academic interests. As a consequence of funding pressures, internationalization priorities and donor shifts, their motivation to engage in collaboration with institutions in Africa has dwindled. This is unfortunate for two reasons: after decades of cooperation and support, quite a number of universities in Africa have become better and stronger institutions. First, they may not yet feature high in the global rankings but may make strategic partners in the global knowledge networks that emerge. Second, a number of African countries are showing 
impressive economic growth figures and will be the economic partners of tomorrow, as has happened with the BRIC countries. For economic and academic reasons, it is logical that academic collaboration with African institutions gets proper attention.

\section{New Directions}

However, certain conditions need to be met for Northern institutions (especially those in northern Europe), to engage in partnerships and collaborations with African institutions:

- Institutions in the North should broaden their strategic horizons from a short-term, profit-oriented and egocentric perspective-to a longerterm, global perspective. They need to be aware of the fact that the world is changing rapidly and that opportunities are changing as well. Problems and research questions are increasingly becoming global, and solutions likewise need to be developed on a global scale with the collaboration of local partners.

- African institutions should show more self-confidence and argue the case for true partnerships. Although they may not be able to contribute at the same level based on the start of collaboration, nevertheless they have valuable possible contributions. In time, the scale will level and possibly swing to the other side.

- Mutual benefits form the best foundation for establishing sustainable collaborations. This can be arranged on the basis of sound analysis and negotiations, proper planning, give-and-take, and respect for one 
another. Returns from such partnerships are uncertain and long term; development cooperation funds are less available for establishing longterm collaborations. Institutions should be prepared to invest in partnerships, not only in those with low-risk returns but also in those with higher-risk collaborations with lower-ranking partners.

- Governments in the North should try to create greater coherence among policy areas, especially those of education, development cooperation, economic, and foreign affairs. International collaboration in higher education and research touches all these spheres, and it would help academic institutions a great deal if these policies were coherent and complementary. With Germany as one of the few notable exceptions, policies of the national ministries in Northern countries are neither coherent nor conducive to engaging in international partnerships and longer-term academic collaborations.

- Development cooperation programs that fund such collaborations should allow some room for institutions to identify and formulate collaboration with partners that not only contribute to ministerial policy goals but also to their own mission and strategy. This presumes a balance between different interests by the stakeholders involved.

Collaboration with African institutions should be of strategic interest for academic institutions in the North, yet this requires a clear vision by institutional leaders and a coherent policy framework that stimulates and supports such efforts. 